Research Article

\title{
CRASHWORTHINESS INVESTIGATION OF VEHICLE FRONT BUMPER BEAM WITH DIFFERENT CROSS-SECTIONS UNDER AXIAL DYNAMIC LOAD
}

\begin{abstract}
Hüseyin BEYTÜT ${ }^{1}$, Selçuk KARAGÖZ2 ${ }^{2 *}$, Serkan ÖZEL ${ }^{3}$
Bumper beam, is one of the first structures exposed to impact at the time of an accident. Therefore, how it behaves at the time of an accident is extremely important in terms of passenger safety, cargo and other critical parts of the vehicle. What is expected from a bumper beam is to absorb the kinetic energy of the vehicle through plastic deformation, particularly at low and medium speeds. In this study, finite element models of the crash situations of the bumper beams with five different cross-sectional geometries and equal weights were created by using the HyperMesh software and crash analyses were carried out. Since the bumper beams may behave differently in different barrier types, pole and wall barrier impact test was investigated. AA6061-T6 Aluminum alloy was used as the material and Johnson-Cook was used as the material model. The results revealed that the cross-sectional geometry had significant effect on crashworthiness and the models exhibited different crashworthiness on wall and pole barriers. RADIOSS/explicit and non-linear finite element codes were used.
\end{abstract}

Keywords: Vehicle bumper beam; energy absorption; finite element method; crashworthiness.

\section{Introduction}

In today's vehicle designs, vehicle crashworthiness and vehicle mitigation have become attractive matters for both automobile manufacturers and researchers [1, 2]. Crashworthiness is an engineering term used to describe the ability of a vehicle structure to protect its occupants during a crash [3]. The importance of vehicle crashworthiness is constantly increasing due to strict safety norms, high competition and increasing safety concerns.

Bumper beams, which are among the passive safety systems in vehicles, are important structural elements for vehicle crashworthiness. Since the bumper beam is one of the main parts that absorbs vehicle crash energy, its design and production are extremely critical for an efficient energy absorption

1 Department of Mechanical Engineering, Bitlis Eren University, Bitlis, Turkey, (hbeytut@beu.edu.tr) (Dhttps://orcid.org/0000$0001-8751-2225$

2 * Department of Mechanical Engineering, Bursa Technical University, Bursa, Turkey, (selcuk.karagoz@btu.edu.tr) https://orcid.org/0000-0002-1987-5750

3 Department of Mechanical Engineering, Bitlis Eren University, Bitlis, Turkey, (sozel@beu.edu.tr) (D) https://orcid.org/00000003-0700-1295 
[4]. Bumper beams are impact absorber structures located in the front and rear of the vehicle and whose primary function is to protect critical parts of the vehicle and occupants. Bumper beams are applied to today's vehicles by being designed with different materials in various geometries with crash boxes.

The main purpose of this dual system is to absorb the kinetic energy of vehicle and to ensure that occupants survive the accident with minimum damage. Since the cross-section of the bumper has effect on the crash performance, it can be designed in different cross-sections [5] (fig. 1).
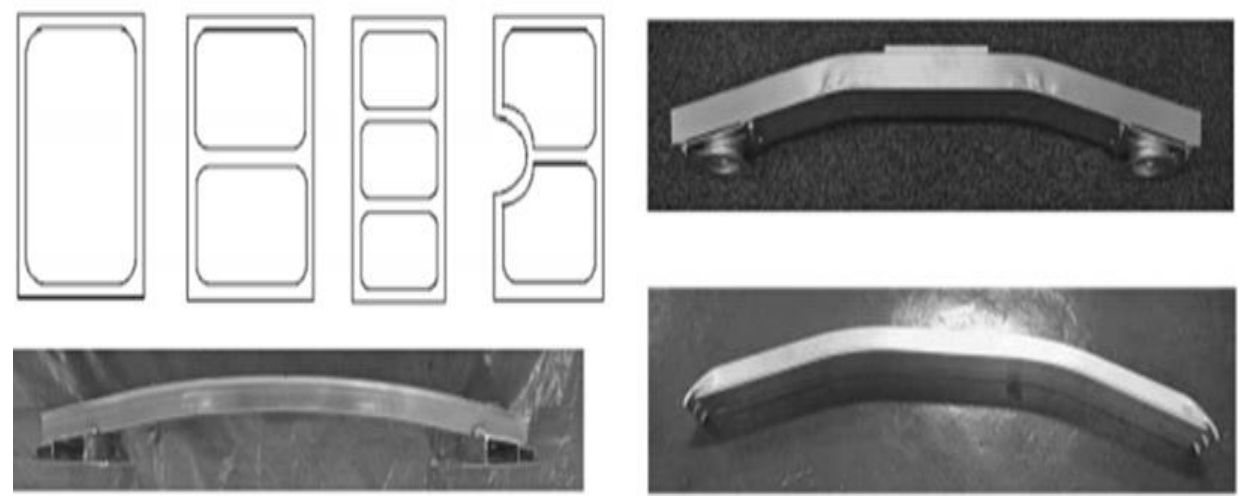

Figure 1. Bumper beam cross-section examples and models [5].

The main physical phenomenon, where the structures used for energy absorption absorb energy, is plastic deformation. Keeping plastic deformation at maximum level is important in terms of the amount of energy that is absorbed. Therefore, the material used needs to be stiff but deformable [6-8]. A non-deformable structure will act as rigid and transmit the force to the other parts without performing its essential task which is energy absorption.

Cross-section [9, 10], material [11, 12], wall thickness [13], loading conditions [14], which are the main parameters that significantly affect crashworthiness of bumper beam, are the most studied subjects by researchers. Certain parameters have been determined in the determination of crashworthiness of energy absorbing structures. The most important ones are the amount of absorbed energy, peak crushing force, mean crushing force, crash force efficiency and specific energy absorption.

\subsection{Absorbed Energy (AE)}

The amount of absorbed energy by bumper beam can be found in the area below the forcedisplacement curve (Equation 1).

$$
\mathrm{AE}=\int_{0}^{\mathrm{d}} \mathrm{P}(\mathrm{x}) \mathrm{dx}
$$

Where; $\mathrm{d}$ refers to displacement and $\mathrm{P}(\mathrm{x})$ refers to the force in the axial direction.

\subsection{Peak Crushing Force (PCF)}

Peak crushing force generally occurs on the first reaction force if the trigger mechanism (groove, hollow, hole) is not used. It is expected to be low in terms of the force to be transmitted to the occupants at the time of an accident.

\subsection{Mean Crushing Force (MCF)}

The mean crushing force value is found by the ratio of $\mathrm{AE}$ to displacement (Equation 2). In order to keep the $\mathrm{AE}$ at the maximum level, it is a desired situation that the forces after the first reaction force are close to the mean crushing force. 


$$
\mathrm{P}_{\mathrm{o}}=\frac{\mathrm{AE}}{\mathrm{d}}
$$

\subsection{Crash Force Efficiency (CFE)}

Crash force efficiency ( $\eta$ ) is calculated by the ratio of the MCF to the PCF (Equation 3). It is an important parameter in evaluating the crashworthiness of the structure since it depends on both the $\mathrm{AE}$ and PCF $\left(\mathrm{P}_{\max }\right)$.

$$
\eta=\frac{P_{o}}{P \max }
$$

\subsection{Specific Energy Absorption (SEA)}

It is calculated by the ratio of the AE to the mass of the structure (Equation 4). Since all models in this study have equal weights, the absorbed energy rates will be equal to the specific energy absorption rates.

$$
\mathrm{SEA}=\frac{\mathrm{AE}}{\mathrm{m}}
$$

\section{Material and Method}

In addition to the energy absorption property of bumper designs, lightness, ease of production and being economic are also expected. Steel, aluminum, magnesium alloys and polymeric-based composites are main materials used as bumper beam material [15]. In this study, Aluminum 6061-T6 alloy was used as the bumper material. Johnson-Cook material model [16], which represents the isotropic elasto-plastic material was used due to the fact that the vehicle front structure components used for energy absorption are subjected to significant plastic deformations in a very short time at the time of an accident and due to the effect of strain rate on crashworthiness. Johnson-Cook material model is often used in dynamic analyses since it pays attention to the strain rate, hardening and temperature effect [17-19]. In this study, temperature influence was neglected. The mechanical properties and Johnson-Cook parameters belonging to aluminum 6061-T6 alloy are given in Table 1.

Table 1. Mechanical properties of AL6061-T6 alloy and Johnson-Cook parameters [20].

\begin{tabular}{c|c|c|c|c|c|c}
\hline $\boldsymbol{E}(\mathbf{G P a})$ & $\boldsymbol{\rho}\left(\mathbf{g r} / \mathbf{c m}^{3}\right)$ & $\boldsymbol{v}$ & $\boldsymbol{A}(\mathbf{G P a})$ & $\boldsymbol{B}(\mathbf{G P a})$ & $\boldsymbol{n}$ & $\boldsymbol{C}$ \\
\hline 70 & 2.7 & 0.33 & 324 & 114 & 0.42 & 0.002 \\
\hline
\end{tabular}

Where $\mathrm{A}$ is the yield stress, $\mathrm{B}$ is hardening parameter, $\mathrm{n}$ is hardening exponent and $\mathrm{C}$ is strainrate coefficient. Bumper models was designed as surface on CATIA software in a way to have the same surface area $\left(0.357 \mathrm{~m}^{2}\right)$ in 5 different geometries (Figure 2). In model 2, model 3 and model 4 designs, outward or inward hollows were formed. In this way, it was aimed to reduce the peak crushing force by allowing easier folding.

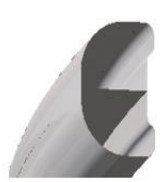

Model 1

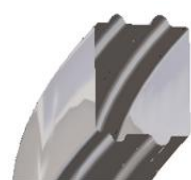

Model 2

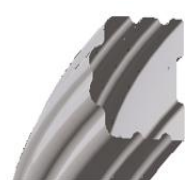

Model 3

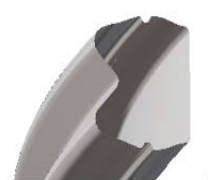

Model 4

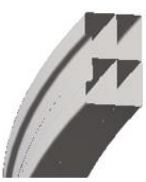

Model 5

Figure 2. Bumper beam models designed in 5 different cross-sectional geometries and in the same weight. 
Each bumper weight is calculated as approximately $1155 \mathrm{~g}$ for $1.2 \mathrm{~mm}$ wall thickness and 2700 $\mathrm{kg} / \mathrm{m}^{3}$ density. Shell elements in the size of $2.5 \times 2.5$ were used for mesh by using HyperMesh software. As contact definition, "Nodes to Surface Contact", which ideally represents the model in dynamic analyses and uses penalty method, was used [21, 22]. During folding, the friction coefficient between the surfaces of the bumper beams and between the bumper beam and the wall and pole barriers was accepted as 0.2 and Coulomb's law of friction was used [23, 24]. The created pole and wall barriers were defined as rigid to prevent deformation. $1225 \mathrm{~kg}$ mass was added to the bumper beams to provide a real crash environment and they were crashed to straight wall and pole barriers with $56 \mathrm{~km} / \mathrm{h}$. In addition, all models were restricted from other degrees of freedom except the axis to which the speed was provided (Figure 3).

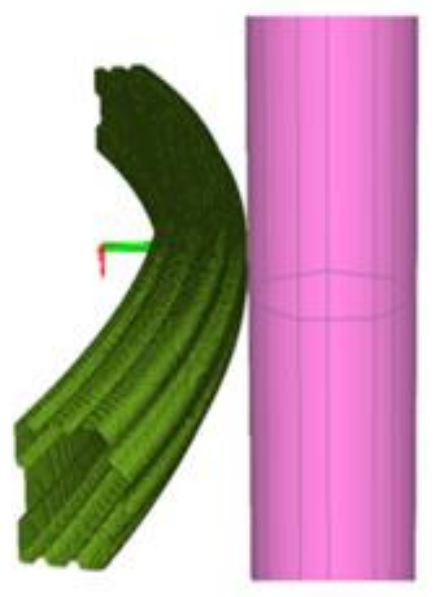

(a)

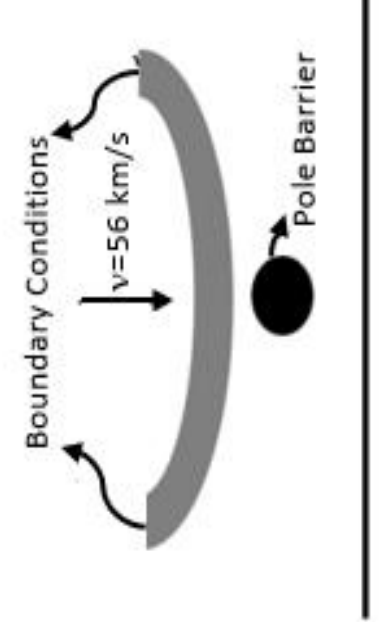

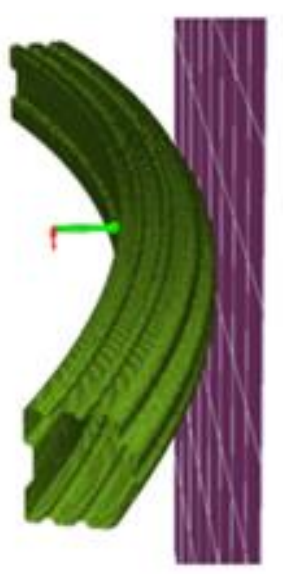

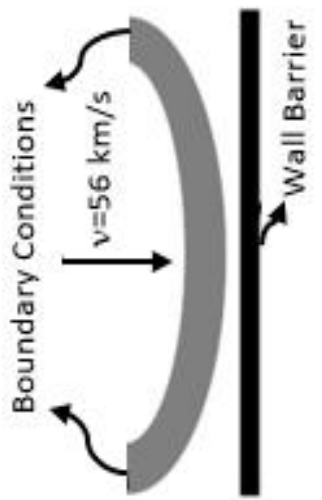

(b)

Figure 3. Model 3's finite element model and schematic representation regarding a) pole barrier b) wall barrier.

Since the bumper beam under dynamic load was subjected to very high plastic deformation in a very short time, explicit method was used. In the explicit method, the total analysis time is divided into much smaller time intervals which are named as time steps. The statement regarding the time step is given in Equation 5 and Equation 6.

$$
\begin{aligned}
& \Delta t_{e}=\frac{l}{c} \\
& c=\sqrt{\frac{E}{\rho}}
\end{aligned}
$$

Here; $l$ represents the smallest distance between the 2 nodal points of the element, c represents the sound velocity of the material, $E$ represents the elasticity modulus of the material and $\rho$ represents the density of the material. As the size of the element used in the formation of the mesh becomes smaller and the elasticity modulus of the material increases, the time step will become smaller and thus, the solution time will extend. In this study, the time step varies between 1.966 E-4 and 3.321 E-4 depending on the model.

\section{Results and Discussion}

The deformation conditions occurring on the wall and pole barriers of the bumper beam models designed for each geometry at the end of the crash analyses are shown in Figure 4. While off-center 
deformation was observed on the pole barrier, deformations also occurred on the sides on the wall barrier. In addition, stresses were at maximum level on these areas because the end parts of all models were restricted to other degrees of freedom except the axis in which the speed was provided.

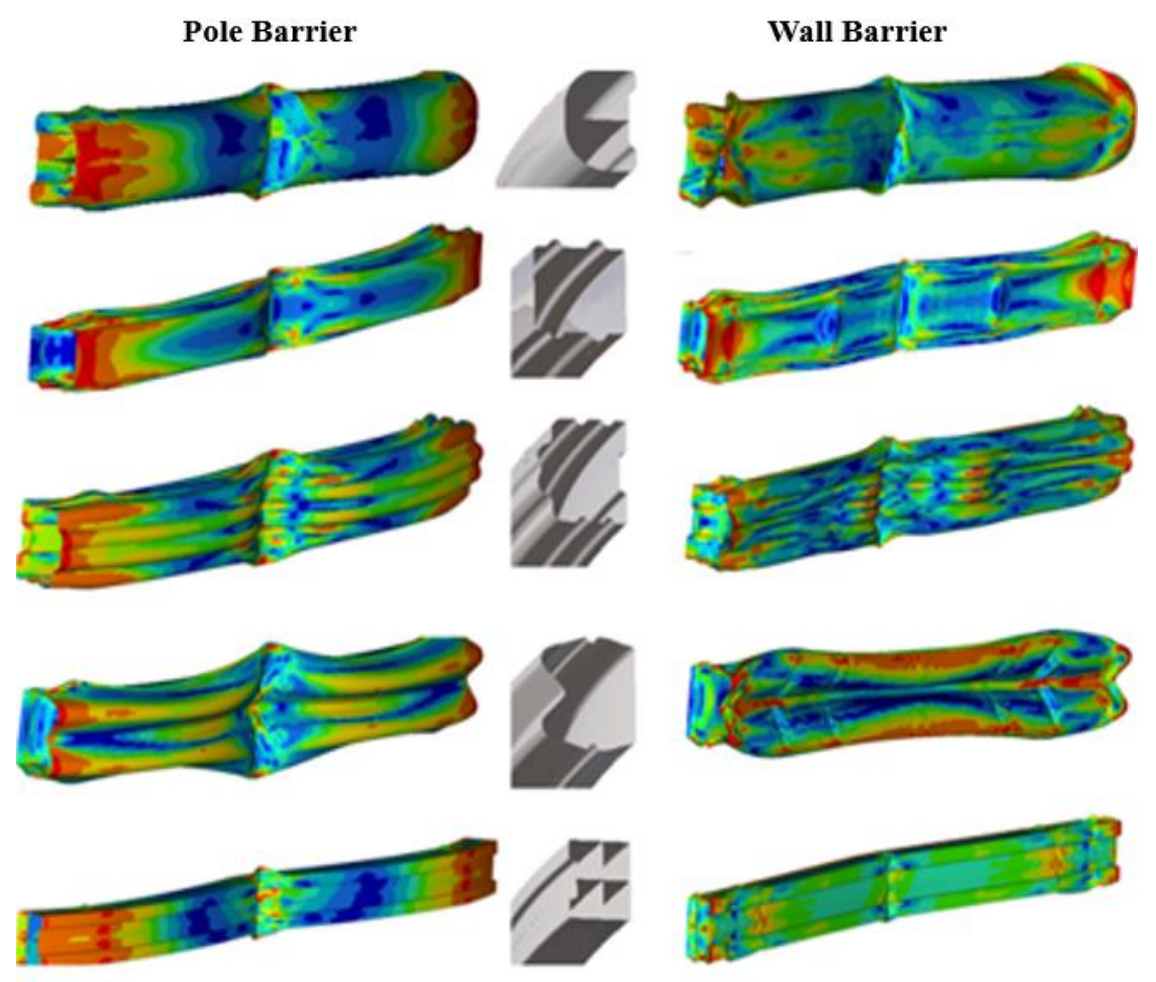

Figure 4. Models' deformation conditions on rigid pole and wall barriers and Von Mises stress distributions.

It is a desired situation that the reaction force, which is an important criterion in the evaluation of crashworthiness, is low in terms of occupant and transported cargo safety. In order to reduce the peak crushing force that usually occurs in the first reaction force, hollows were added to Model 2, Model 3 and Model 4. Thanks to the added hollows, the peak crushing force in these models was found to be lower than in other models. On the rigid wall barrier, the highest crushing force was achieved in Model 5 and the lowest in Model 1 (fig. 5).

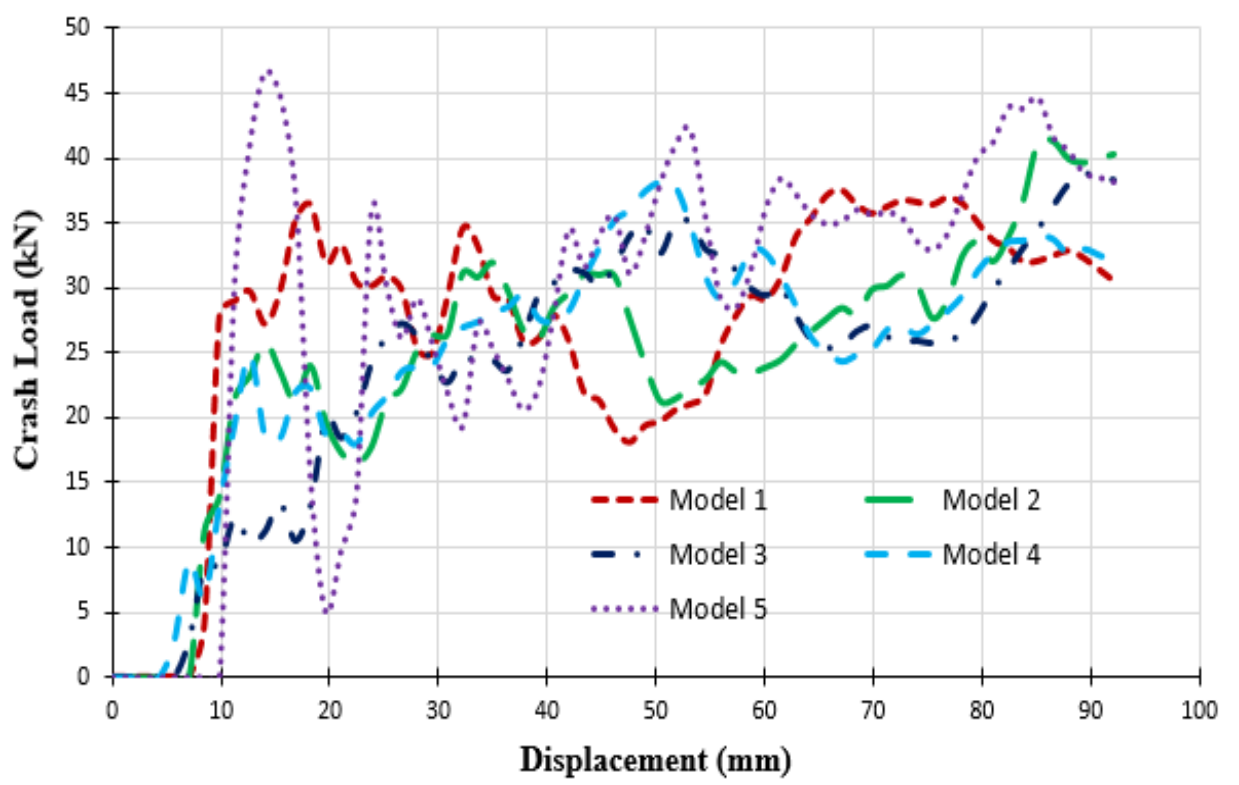

Figure 5. Crash load versus displacement curves for rigid wall barrier. 
Peak crushing forces on the pole barrier of the models with hollows were also lower as on the wall barrier. In terms of both wall barrier and pole barrier, the first reaction force of the Model 3 was found to be the lowest and the Model 5 was found to be the highest. This situation is thought to be caused by the fact that the Model 5 did not have any hollow and its cross-sectional geometry was straighter than other models.

For all models, the peak crushing force on the wall barrier was higher than the pole barrier. The reaction forces of the models occurring on the rigid pole barrier are given in Figure 6. In the Model 1 with no hollow, the peak crushing force occurred at the first reaction force, while it occurred at the next reaction forces in other models. On the rigid pole barrier, the highest crash load was obtained in the Model 5 and the lowest in the Model 2.

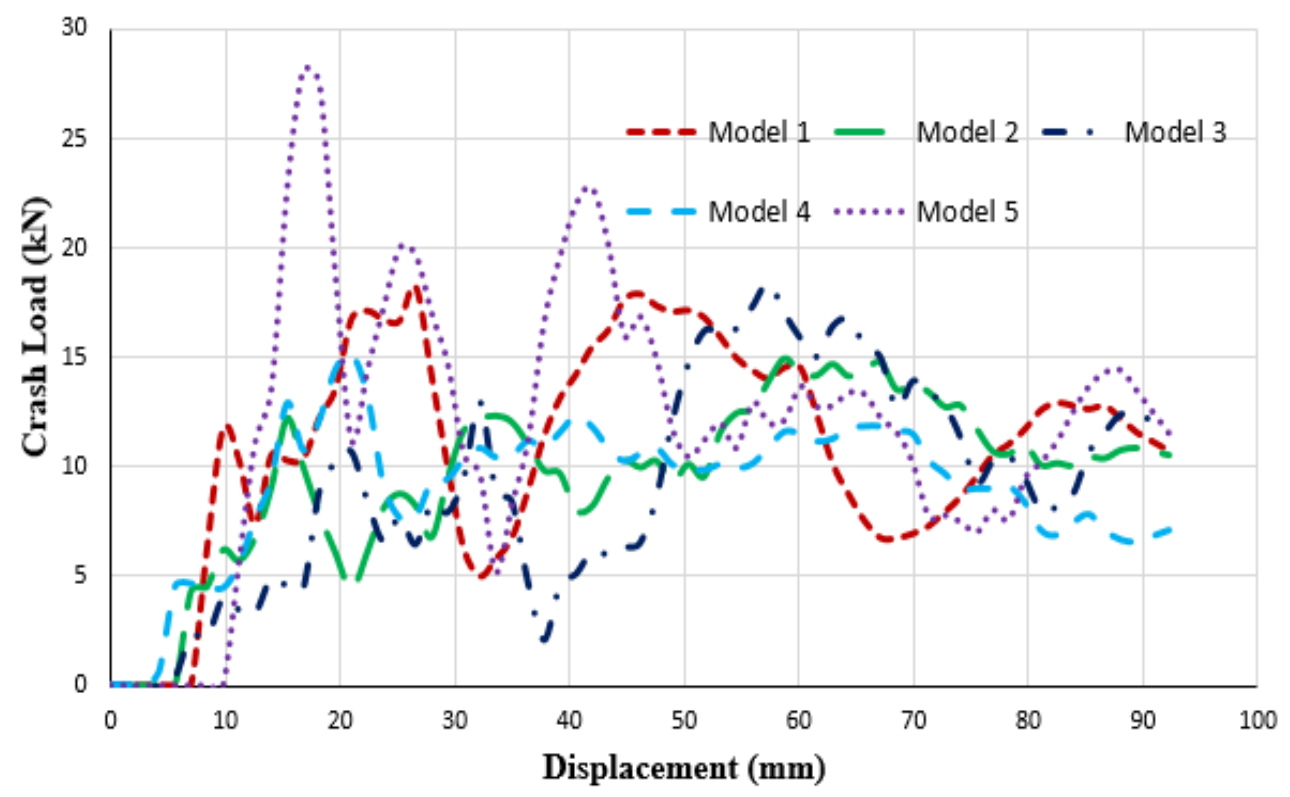

Figure 6. Crash load versus displacement curves for rigid pole barrier.

The amount of absorbed energy by the models on the wall barrier is given in Figure 7. The Model 5 has the most energy absorption, while the Model 3 has the lowest energy absorption.

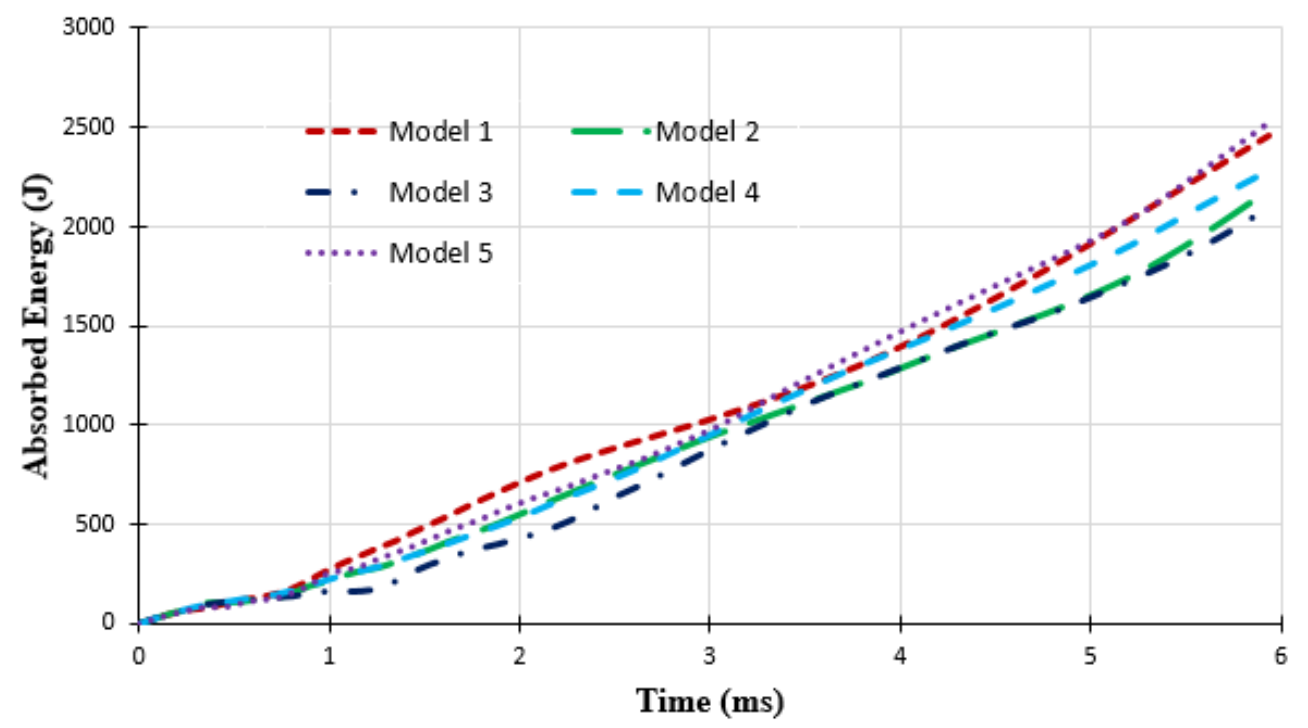

Figure 7. Absorbed energy versus time curves for rigid wall barrier. 
The amount of absorbed energy by the models on the pole barrier is given in Figure 8. The Model 5 has the highest energy absorption, while the Model 4 has the lowest energy absorption.

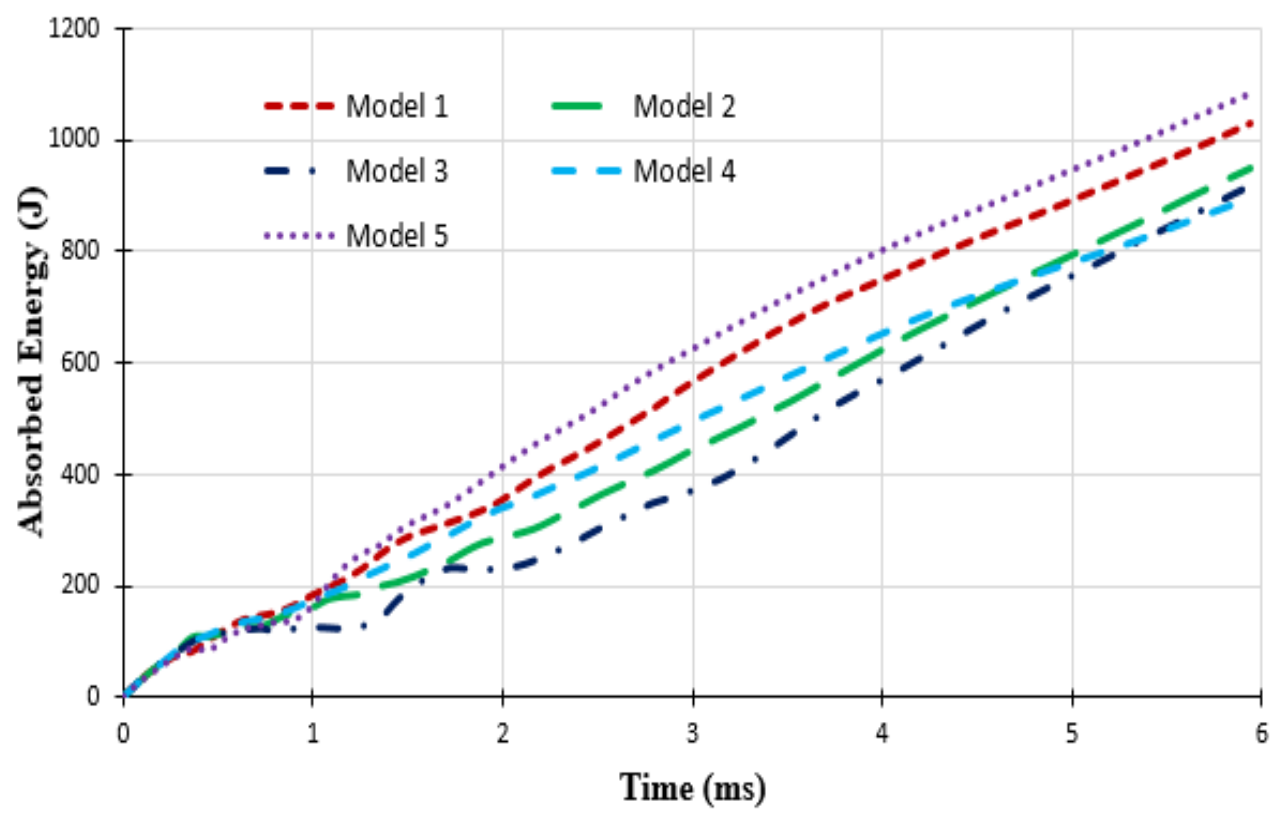

Figure 8. Absorbed energy versus time curves for rigid pole barrier.

Since all bumper beam models had a more homogeneous plastic deformation on the wall barrier, they achieved more energy absorption compared to the pole barrier. At the same time, their peak crushing forces were also higher. When the analysis results are evaluated, it is seen that the highest absorbed energy (AE) value was obtained in the Model 5 in terms of both pole and wall barrier. The lowest peak crushing force (PCF) was obtained in the Model 1 for rigid wall barrier and Model 4 for rigid pole barrier. When the results are evaluated in terms of crash force efficiency (CFE) depending on both $\mathrm{AE}$ and MCF, the best result was obtained in the Model 1 for rigid wall barrier and Model 2 for rigid pole barrier. Dynamic analysis results for all models are given in Table 2.

Table 2. Dynamic analysis results for all models.

\begin{tabular}{c|c|c|c|c|c|c|c|c}
\hline \multirow{2}{*}{$\begin{array}{c}\text { Model } \\
\text { No }\end{array}$} & \multicolumn{4}{|c|}{ Rigid Wall Barrier } & \multicolumn{5}{c}{ Rigid Pole Barrier } \\
\hline AE (J) & PCF (kN) & MCF (kN) & CFE & \multicolumn{1}{c}{ AE (J) } & PCF (kN) & MCF (kN) & CFE \\
\hline Model 1 & 2456.70 & 37.56 & 26.65 & 0.709 & 1029.33 & 18.20 & 11.15 & 0.612 \\
\hline Model 2 & 2189.75 & 41.22 & 23.75 & 0.576 & 949.51 & 14.94 & 10.28 & 0.688 \\
\hline Model 3 & 2094.02 & 38.79 & 22.72 & 0.586 & 920.08 & 18.44 & 9.96 & 0.540 \\
\hline Model 4 & 2282.18 & 38.14 & 24.76 & 0.649 & 895.58 & 15.10 & 9.70 & 0.642 \\
\hline Model 5 & 2524.40 & 46.74 & 27.39 & 0.586 & 1082.20 & 28.19 & 11.72 & 0.415 \\
\hline
\end{tabular}

\section{Conclusion}

The peak crushing force is expected to be low and the absorbed energy is expected to be high in the values obtained as a result of crash analyses. 5 different bumper beams having the same weight were modeled and crashworthiness under dynamic load was investigated. In order to reduce the peak crushing force that usually occurs at the first reaction force, hollows were added to some models. It was observed that the first reaction force was lower in the models with hollow and it was concluded that the first reaction force could be reduced by adding hollow. 
When finite element analysis of the models is evaluated, it is seen that the highest energy absorption was achieved in the Model 5 with $2524.40 \mathrm{~J}$ for rigid wall barrier and $1082.2 \mathrm{~J}$ for rigid pole barrier. However, in the Model 5, the peak crushing force values were $46.74 \mathrm{kN}$ for the rigid wall barrier and $28.19 \mathrm{kN}$ for the rigid pole barrier, and these are the highest values for all models. This situation is thought to be caused by the fact that the Model 5 did not have any hollow and its cross-sectional geometry was straighter than other models. Although the Model 5 has the highest energy absorption value, it is considered negative because the peak crushing force is much higher than other designs. When the results are evaluated in terms of crash force efficiency depending on both absorbed energy amount and peak crushing force, it was obtained in the Model 1 with 0.709 for rigid wall barrier and in Model 2 with 0.688 for rigid pole barrier. Since the Model 1 has more stable reaction forces for rigid wall barrier and Model 2 for rigid pole barrier, these designs come to the forefront compared to other designs.

The results reveal that the minor changes made in the cross-sectional geometry of bumper beam affect crashworthiness and the first reaction force can be reduced by adding hollows to bumper beam. Furthermore, the models showed different crashworthiness on rigid wall and pole barriers. Therefore, it is important to perform analyses not only for a barrier type but also all possible barrier types of the bumper beam to be mounted to the vehicle in terms of the vehicle crashworthiness.

\section{References}

[1] Sun, G.Y., G.Y. Li, S.W. Zhou, H.Z. Li, S.J. Hou, and Q. Li,(2011) Crashworthiness design of vehicle by using multiobjective robust optimization. Structural and Multidisciplinary Optimization. 44(1): p. 99-110, doi:10.1007/s00158-010-0601-z.

[2] Yang, R.J., N. Wang, C.H. Tho, and J.P. Bobineau,(2005) Metamodeling development for vehicle frontal impact simulation. Journal of Mechanical Design. 127(5): p. 1014-1020, doi:10.1115/1.1906264.

[3] Jones, N., Structural impact. Cambridge: Cambridge university press. 2011

[4] Cheon, S.S. and J.H. Choi,(1995) Development of the composite bumper beam for passenger cars. Composite Structures. 32(1-4): p. 491-499, doi:10.1016/0263-8223(95)00078-X.

[5] Hashimoto, N.,(2017) Application of Aluminum Extrusions to Automotive Parts. Kobelco Technology Review, (35): p. 69-75.

[6] Safari, H., H. Nahvi, and M. Esfahanian,(2018) Improving automotive crashworthiness using advanced high strength steels. International Journal of Crashworthiness. 23(6): p. 645-659, doi:10.1080/13588265.2017.1389624.

[7] Wierzbicki, T. and W. Abramowicz,(1983) On the Crushing Mechanics of Thin-Walled Structures. Journal of Applied Mechanics-Transactions of the Asme. 50(4a): p. 727-734, doi:Doi 10.1115/1.3167137.

[8] Khatri, N.A., H. Shaikh, Z.A. Maher, A. Shah, and S.F. Ahmed,(2018) A Reviewon Optimization of Vehicle Frontal Crashworthiness for Passenger Safety. International Journal of Engineering \& Technology. 7(2.34): p. 1-4, doi:10.14419/ijet.v7i2.34.13894.

[9] Patil, S.A., R. Moradi, and H.M. Lankarani. Vehicle mass optimization for frontal structure using I-sight and study of weld parameterization for mass improvement. in ASME 2014 International Mechanical Engineering Congress and Exposition. 2014. American Society of Mechanical Engineers.

[10] Zhang, Z.H., S.T. Liu, and Z.L. Tang,(2009) Design optimization of cross-sectional configuration of rib-reinforced thin-walled beam. Thin-Walled Structures. 47(8-9): p. 868-878, 
doi:10.1016/j.tws.2009.02.009.

[11] Belingardi, G., A.T. Beyene, E.G. Koricho, and B. Martorana,(2015) Alternative lightweight materials and component manufacturing technologies for vehicle frontal bumper beam. Composite Structures. 120: p. 483-495, doi:10.1016/j.compstruct.2014.10.007.

[12] Ding, M., J. Liu, B. Liu, X. Wang, T. Li, and D. Cao. On the development of automotive composite material rear bumper beam. in Proceedings of SAE-China Congress 2015: Selected Papers. 2016. Springer.

[13] Wang, G., J. Zhou, Z. Liu, L. Li, B. Liu, X. Li, et al.,(2012) Lightweight design and crash performance analysis of automotive aluminum bumper. The Chinese Journal of Nonferrous Metals. 22(1): p. 90-98.

[14] Hosseinzadeh, R., M.M. Shokrieh, and L.B. Lessard,(2005) Parametric study of automotive composite bumper beams subjected to low-velocity impacts. Composite Structures. 68(4): p. 419-427, doi:10.1016/j.compstruct.2004.04.008.

[15] Tanlak, N., F.O. Sonmez, and M. Senaltun,(2015) Shape optimization of bumper beams under high-velocity impact loads. Engineering Structures. 95: p. 49-60, doi:10.1016/j.engstruct.2015.03.046.

[16] Johnson, G.R.,(1983) A constitutive model and data for materials subjected to large strains, high strain rates, and high temperatures. Proc. 7th Inf. Sympo. Ballistics: p. 541-547.

[17] Wang, Q., F. Wu, B. Tang, and C. Li. Damage Behavior of Boron Steels with Various Hardness Using the GTN and the Johnson-Cook Model. in Advanced High Strength Steel And Press Hardening-Proceedings Of The 4th International Conference On Advanced High Strength Steel And Press Hardening (Ichsu2018). 2018. World Scientific.

[18] Raman, R., K. Jayanth, I. Sarkar, and K. Ravi. Analyzing the effect of carbon fiber reinforced polymer on the crashworthiness of aluminum square hollow beam for crash box application. in IOP Conference Series: Materials Science and Engineering. 2017. IOP Publishing.

[19] Estrada, Q., D. Szwedowicz, A. Rodriguez-Mendez, M. Elías-Espinosa, J. Silva-Aceves, J. Bedolla-Hernández, et al.,(2019) Effect of radial clearance and holes as crush initiators on the crashworthiness performance of bi-tubular profiles. Thin-Walled Structures. 140: p. 43-59, doi:10.1016/j.tws.2019.02.039.

[20] Lesuer, D.R., G. Kay, and M. LeBlanc, Modeling large-strain, high-rate deformation in metals. 2001, Lawrence Livermore National Lab., CA(US).

[21] Gumruk, R. and S. Karadeniz,(2009) The influences of the residual forming data on the quasistatic axial crash response of a top-hat section. International Journal of Mechanical Sciences. 51(5): p. 350-362, doi:10.1016/j.ijmecsci.2009.03.010.

[22] Toksoy, A.K. and M. Guden,(2010) Partial Al foam filling of commercial 1050H14 Al crash boxes: The effect of box column thickness and foam relative density on energy absorption. ThinWalled Structures. 48(7): p. 482-494, doi:10.1016/j.tws.2010.02.002.

[23] Ahmad, Z. and D.P. Thambiratnam,(2009) Dynamic computer simulation and energy absorption of foam-filled conical tubes under axial impact loading. Computers \& Structures. 87(3-4): p. 186-197, doi:10.1016/j.compstruc.2008.10.003.

[24] Zheng, G., T. Pang, G.Y. Sun, S.Z. Wu, and Q. Li,(2016) Theoretical, numerical, and experimental study on laterally variable thickness (LVT) multi-cell tubes for crashworthiness. International Journal of Mechanical Sciences. 118: p. 283-297, doi:10.1016/j.ijmecsci.2016.09.015. 